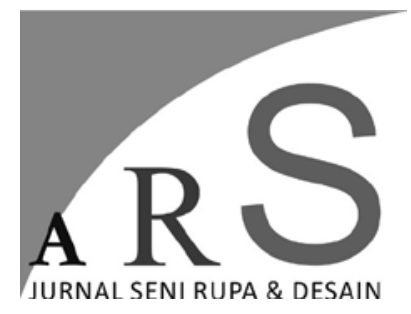

Vol 24 No 1 Januari - Maret $20219-14$

\section{EKSPERIMENTASI KLUWIH (ARTOCARPUS CAMANSI) SEBAGAI WARNA ALAM PADA TEKSTIL}

\author{
Djandjang Purwo Sedjati ${ }^{1}$, Zahra Azkia Putri Yantari ${ }^{2}$ \\ 1,2 Program Studi S-1 Kriya, Fakultas Seni Rupa, \\ Institut Seni Indonesia Yogyakarta \\ Tlp. 08122791265, E-mail: mrs.djandjang@gmail.com
}

\begin{abstract}
ABSTRAK
Berbagai macam tumbuhan dapat digunakan sebagai pewarna tekstil. Namun sejak ditemukannya zat warna sintetis pada abad 19, maka produksi tekstil di Indonesia beralih ke zat warna sintetis. Sayangnya dampak yang ditimbulkan dari limbah zat warna sintetis ini mencemari lingkungan hidup manusia. Pelarangan penggunaan pewarna sintetis di Eropa dan Amerika, serta isu global yaitu Back to Nature, merupakan hal yang tidak mungkin dihindari, bahkan harus dilaksanakan secara konsisten dan berkelanjutan. Produk tekstil juga berhadapan dengan tuntutan selera masyarakat masa kini, yaitu kebutuhan fashion dan interior, serta kebutuhan karyakarya yang dapat memberi kepuasan batin, sehingga diperlukan ciptaan karya baru yang kreatif dan inovatif. Dalam rangka mencari keberagaman dan pengkayaan warna dari tumbuhan yang ada di Indonesia, penulis ingin mengambil tumbuhan Kluwih (Artocarpus camansi) sebagai pewarna alam untuk tekstil dengan teknik celup dan cetak langsung (ecoprint). Metode pustaka, observasi dan eksperimentasi digunakan untuk mengumpulkan data. Metode practice based research digunakan untuk memperoleh pengetahuan baru melalui riset praktek dan hasil riset praktek. Metode eksperimen digunakan untuk mendapatkan ilmu pengetahuan baru terutama pada pewarna alam serta improvisasi jika dalam pelaksanaan menemukan ide-ide baru. Pada terapan warna ini akan dilakukan dengan teknik batik, celup dan ecoprint..
\end{abstract}

Kata kunci: kluwih, warna alam, batik, celup ikat, ecoprint

ABSTRACT

Experimentation of Kluwih (Artocarpus camanis) as a Natural Color in Textile. A wide variety of plants can be used as textile dyes. However, since the discovery of synthetic dyes in the 19th century, textile production in Indonesia has switched to synthetic dyes. Unfortunately, the impact of this synthetic dye waste pollutes the human environment. The ban on the use of synthetic dyes in Europe and America, as well as the global issue, namely Back to Nature, is something that cannot be avoided, and must be implemented consistently and sustainably. Textile products are also dealing with the demands of today's society, namely the need for fashion and interior, as well as the need for works that can give inner satisfaction, so the creation of new creative and innovative works is needed. In order to find the diversity and color enrichment of plants in Indonesia, the author wants to take the Kluwih plant (Artocarpus camansi) as a natural dye for textiles using dyeing and direct printing (ecoprint) techniques. Methods of literature, observation and experimentation were used to collect data. Practice based research methods are used to gain new knowledge through practical research and practical research results. Experimental methods are used to gain new knowledge, especially on natural dyes and improvisation when implementing new ideas. The application of this color will be done with batik, dyeing and ecoprint techniques.

Keywords: kluwih, natural color, batik, tie dye, ecoprint 


\section{Pendahuluan}

Sejak diperkenalkannya zat warna sintetis oleh Belanda di Indonesia, maka pengguna zat warna alam beralih menggunakan zat warna sintetis atau kimia yang mempunyai kelebihan, diantaranya mudah penggunaannya, cepat proses pewarnaannya dan murah harganya, sehingga lebih menguntungkan. Namun sayang dampak yang ditimbulkannya adalah limbah yang mencemari lingkungan hidup, bahkan yang bergugus Azo bersifat karsinogenik yang dapat menyebabkan kanker. Hal ini pula yang mendasari pelarangan masuknya produk tekstil dengan warna sintetis di Eropa dan Amerika. Agar produk tekstil dapat diterima dan dipasarkan di Eropa dan Amerika, maka yang harus dilakukan adalah kembali menggunakan zat warna alam, apalagi adanya isu global yaitu back to nature, maka mau tidak mau produk tekstil harus beralih kembali dengan zat warna alam dan harus dilaksanakan secara konsisten dan berkelanjutan.

Kondisi seperti di atas merupakan peluang dan menjadi tantangan untuk menggali keberagaman tumbuhan sebagai sumber zat warna alam dan sebagai pengkayaan variasi warna yang dihasilkan sekaligus dapat diterapkan pada produk tekstil. Dari pengalaman empiris diketahui bahwa buah Kluwih bila dikupas, daging kupasan itu mengeluarkan getah dan getah akan berubah menjadi warna coklat, dari hal itulah maka dapat diduga bahwa Kluwih mempunyai potensi untuk menjadi pewarna alam

Sebagai seniman dan perancang, maka penelitian ini sekaligus menjadi olah kemampuan dalam menciptakan karya seni tekstil yang kreatif, inovatif dan memiliki kebaruan, sebagaimana yang diungkapkan oleh (Sp, 1990, 2006) bahwa: seni modern justru mengejar novelty, mengejar yang baru, yang lain daripada yang lain. Horizon seni modern tidak mengenal batas kecuali batas kemampuan imajinasi senimannya. Standarnyapun selalu goyah berubah terus, sehingga apa yang sudah kita kenal pada suatu saat bisa saja tidak mungkin diciptakan untuk menyiasati seni yang baru.
Kreativitas adalah dimilikinya kemampuan atau daya untuk mencipta yang bersifat orisinal dan imajinatif. Secara lebih terurai kreativitas merupakan sebuah kemampuan untuk menggunakan imajinasi, wawasan dan kekutatan berfikir serta perasaan dan emosi untuk melahirkan sebuah gagasan baru.

Berangkat dari alasan tersebut di atas, menumbuhkan inspirasi untuk mencari keberagaman tumbuhan dan warna yang dihasilkannya, dalam hal ini penulis mengambil pohon Kluwih (Artocarpus camansi) sebagai sumber pewarna alam yang akan diterapkan pada karya tekstil. Eksperimentasi dilakukan meliputi akar, batang, daun, dan buah.

Pada umumnya pewarnaan dilakukan dengan cara pencelupan, seperti yang dilakukan oleh Shabrina Defti Widyaputri dalam penelitiannya untuk me-redesign pakaian secondhand dengan teknik batik tulis (Widyaputri, 2020). Namun selain itu, dapat pula dilakukan dengan cara kontak langsung antara material zat warna alam dengan kain. Kedua teknik inilah yang akan digunakan dalam pembuatan karya tekstil. Untuk mengetahui daya rekat warna padakain dilakukan dengan 3 cara:

a. Teknik batik,untuk mengetahui daya lekat zat warna kluwih pada kain setelah melalui proses pelorodan, dimana pada proses ini dilakukan pemanasan dan penambahan bahan pelorodan yaitu soda abu.

b. Teknik celup, untuk mengetahui daya lekat zat warna alam kluwih pada kain tanpa melalui pelorodan.

c. Teknik cetak langsung (ecoprint), sesuai dengan namanya ecoprint, maka yang dipakai dalam pencetakan warna adalah bahan alam yaitu tumbuh-tumbuhan yang memiliki kandungan zat warna yang dapat dicetakkan pada permukaan kain. Teknik cetak langsung merupakan rekalatar ecoprint adalah kain dari hasil rekalatar melalui cetak dari bagian tumbuhan tertentu secara langsung melalui proses hammer dan atau steaming (Sedjati, 2019). 
Dalam penelitian ini, untuk mengetahui warna yang dihasilkan daun Kluwih pada kain secara langsung dengan menggunakan teknik steaming.

Digunakannya zat warna alam ini sebagai upaya mengurangi pencemaran lingkungan akibat penggunaan zat warna sintetis. Dari uraian latar belakang di atas muncul pertanyaan bagian tumbuhan Kluwih mana saja yang dapat menghasilkan warna serta warna apa saja yang dihasilkan baik melalui pencelupan maupun cetak langsung dan bagaimana hasil yang diperoleh dari kombinasi teknik-teknik yang digunakan dalam proses pembuatan karya.

\section{Metode Penelitian}

Metode yang digunakan pada penelitian ini adalah Metode Practiced Based Research dan Metode Eksperimen. Dalam penciptaan karya ini akan menggunakan metode Practice Based Research, penelitian berbasis praktek merupakan penyelidikan orisinil yang dilakukan guna memperoleh pengetahuan baru melalui praktek dan hasil praktek tersebut . Lebih dalam, disebutkan bahwa penelitian berbasis praktek merupakan penelitian yang paling tepat digunakan oleh pencipta karena pengetahuan baru yang didapat dari penelitian yang dilakukan dapat langsung diterapkan pada bidang bersangkutan dan peneliti melakukan yang terbaik dengan menggunakan kemampuan mereka dan pengetahuan yang telah dimiliki pada subyek kajian tersebut (Malins, Ure, \& Gray, 1996).

Pada proses penciptaan karya ini untuk proses eksekusinya menggunakan metode action (McNiff, Lomax, \& Whitehead, 1996) dijelaskan bahwa "...penelitian tindakan adalah jalan untuk mendefinisikan dan mengimplementasikan perkembangan profesional yang relevan dengan bidangnya. Yang dilakukan melalui metode ini adalah melakukan percobaan pengambilan warna pada bagian-bagian tumbuhan berupa akar, batang (kulit kayu), daun dan kulit buah, yang diterapkan pada media sutra. Warna yang dihasilkan dari masing-masing bagian akan disajikan dalam tabel.

Sedangkan metode eksperimen dalam hal ini digunakan pada saat pengambilan warna akan dicoba bagian tumbuhan yang diperkirakan mengandung zat warna. Teknik pewarnaan celup dan cetak langsung untuk melihat warna yang dihasilkan, sedangkan untuk melihat daya lekat warna dilakukan melaui pembatikan dan pemanasan (pelorodan).

Metode pengumpulan datanya menggunakan 2 metode, yaitu metode pustaka dan metode observasi. Metode pustaka, melalui buku, majalah, katalog, website maupun literatur termasuk penelitian yang sifatnya kualitatif, yang berkaitan dengan proses penciptaan dan tentang obyek sumber inspirasi yaitu tumbuhan Kluwih. Sedangkan metode observasi dilakukan untuk mendapatkan data tentang obyek yang dijadikan sumber penciptaan.

\section{Hasil dan Pembahasan}

Dari metode pustaka dan observasi dapat diidentifikasikan bagian-bagian Kluwih yaitu: daun, akar, kulit buah dan kulit kayu yang menjadi sumber eksperimen pencarian warna Gambar 1-4).

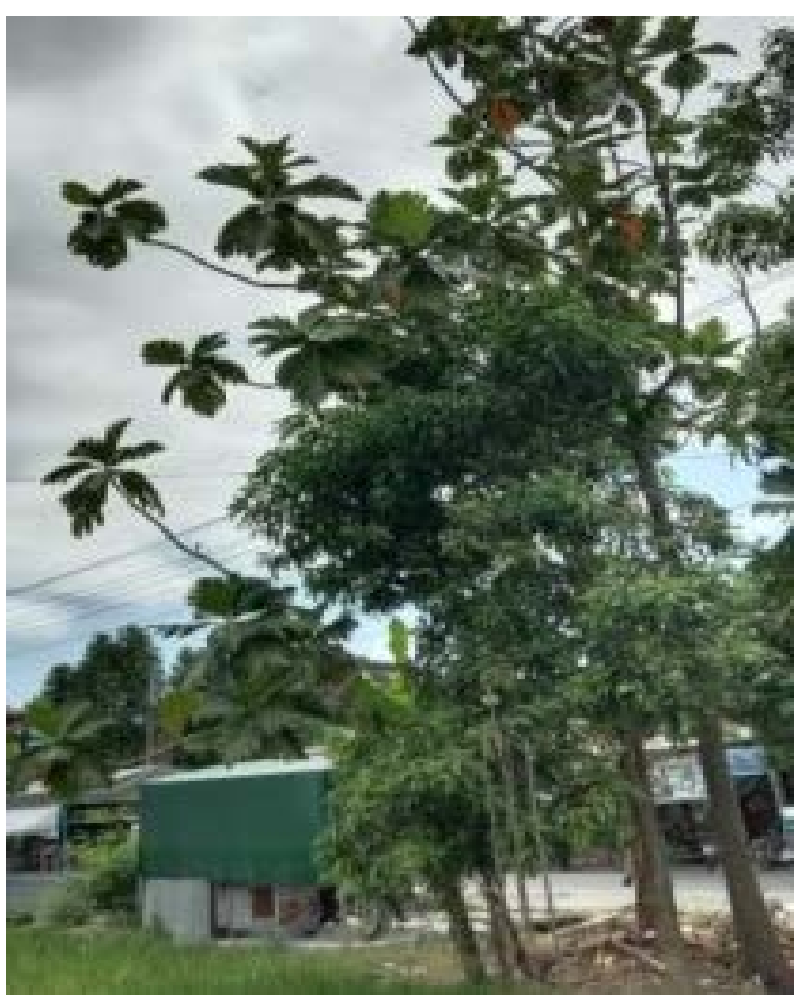

Gambar 1. Pohon Kluwih (Sumber: Dokumentasi Zahra Azkia) 


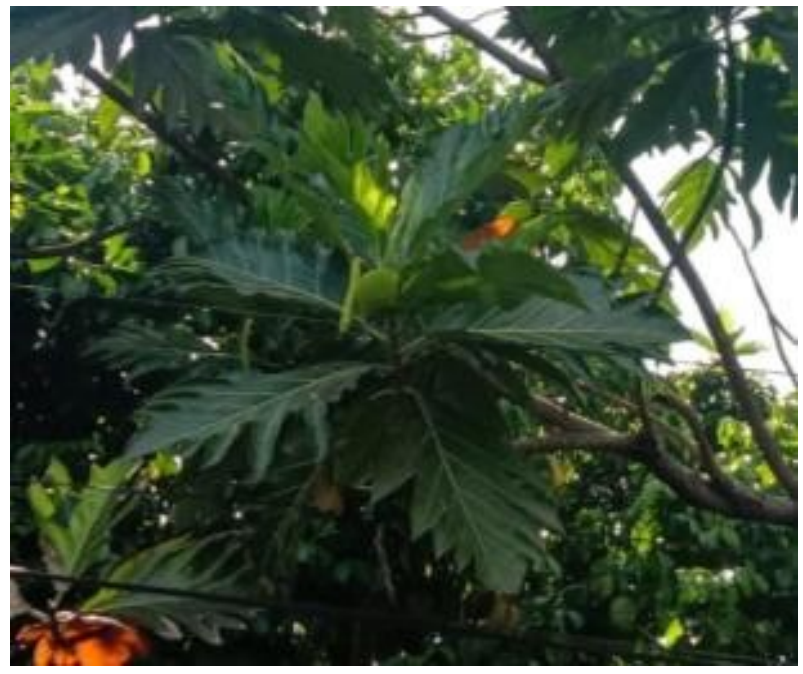

Gambar 2. Daun dan Buah

(Sumber: Dokumentasi Zahra Azkia)

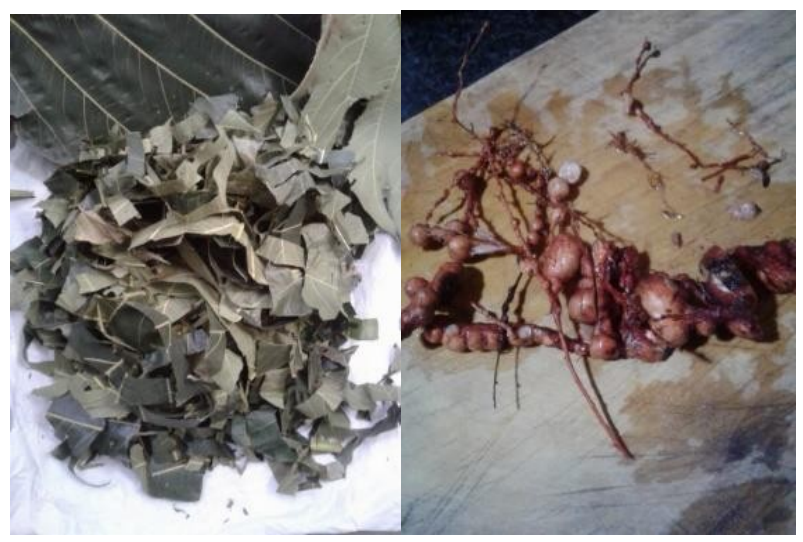

Gambar 3. Daun dan Akar

(Sumber: Dokumentasi Zahra Azkia)

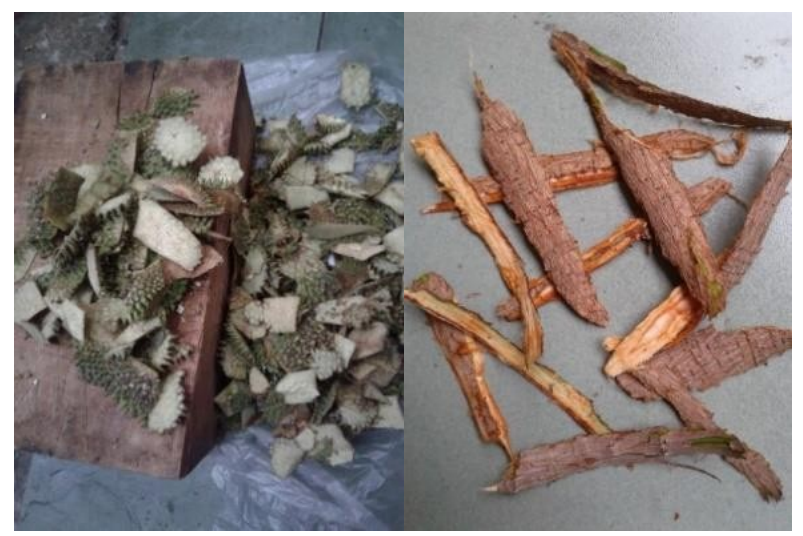

Gambar 4. Kulit Buah \& Kulit Kayu (Sumber: Dokumentasi Zahra Azkia)

\section{Pengolahan Kain Sutra (Mordanting)}

Pada tahap ini bahan dasar (kain sutera) harus dimordant terlebih dahulu supaya nantinya warna alam dapat melekat pada kain dengan maksimal.

Pengolahan ini dilakukan dengan cara merebus sutera dalam larutan tawas. Perbandingan tawas 100 gr: air (kurang lebih 10 liter) selama 1 jam kemudian didiamkan semalam dan esok paginya dicuci bersih dan dikeringkan dengan cara diangin-anginkan.

Eksperimen yang dilakukan meliputi ekperimen ekstraksi daun, akar, buah, kulit kayu, dan eksperimen ecoprinr. Pada eksperimen ekstraksi daun, daun Kluwih yang dipakai adalah daun yang tua dan muda asal tidak daun yang mulai menguning. Daun dicacah kecil-kecil dan kemudian direbus dalam 1 panci stainless atau email. Pengambilan warna dengan cara dasar ekstraksi yaitu bahan warna dicampur dengan air. Satu kg daun Kluwih ditindih menggunakan angsang lalu di atasnya diberi batu agar daun tidak naik ke atas dan air di atas angsang sekitar $2 \mathrm{~cm}$. Daun Kluwih direbus kurang lebih selama satu jam. Setelah dingin air rebusan disaring agar bersih dari ampas. Hasil eksperimen ekstraksi daun diperlihatkan Tabel 1.

Selanjutnya, eksperimen ekstraksi akar. Pada eksperimen ini yang dipakai adalah akar dari pohon Kluwih. Akar di cuci bersih dan kemudian direbus dalam 1 panci stainless atau email. warna dapat keluar dengan maksimal. Pengambilan warna dengan cara dasar ekstraksi yaitu bahan warna dicampur dengan air. $0,5 \mathrm{~kg}$ akar Kluwih ditindih menggunakan angsang lalu di atasnya diberi batu agar akar tidak naik ke atas dan air di atas angsang sekitar $2 \mathrm{~cm}$. Hasil eksperimen ekstraksi akar tampak pada Tabel 1.

Berikutnya adalah eksperimen ekstraksi kulit buah. Pada eksperimen ini yang dipakai adalah kulit buah dari pohon Kluwih. Buah dikupas dahulu untuk diambil kulitnya saja dan kemudian direbus dalam 1 panci stainless atau email. Pengambilan warna dengan cara dasar ekstraksi yaitu bahan warna dicampur dengan air. Satu kilogram (1 kg) kulit buah Kluwih ditindih menggunakan angsang lalu di atasnya diberi batu agar kulit buah tidak naik ke atas dan air di atas angsang sekitar $2 \mathrm{~cm}$. Kulit buah Kluwih direbus 
Tabel 1. Hasil Eksperimen Ekstraksi Daun, Akar, dan Kulit buah

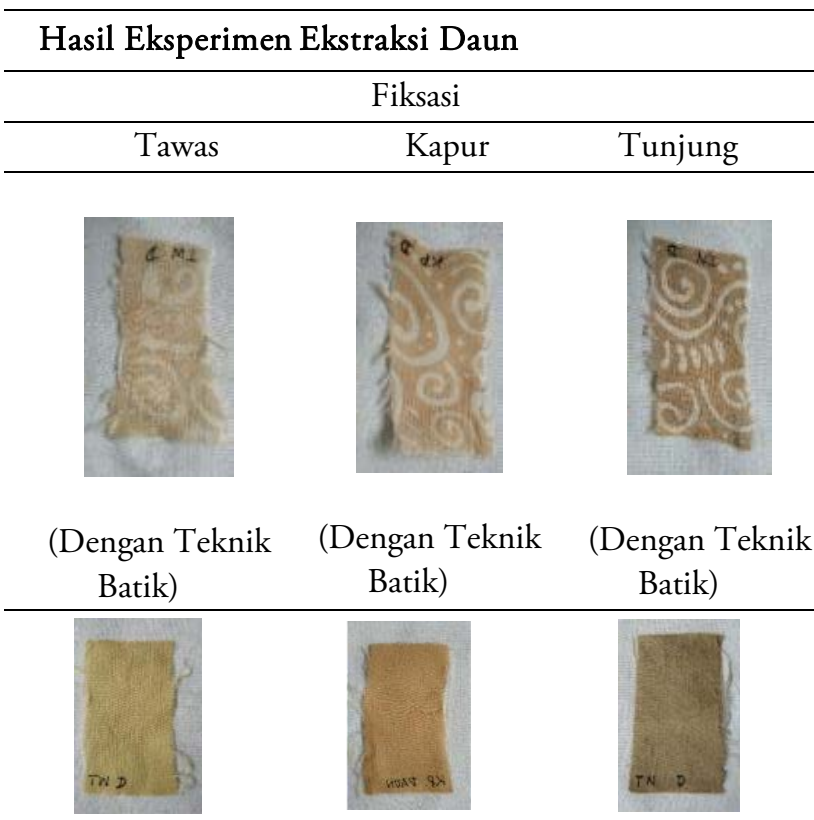

Hasil Eksperimen Ekstraksi Akar

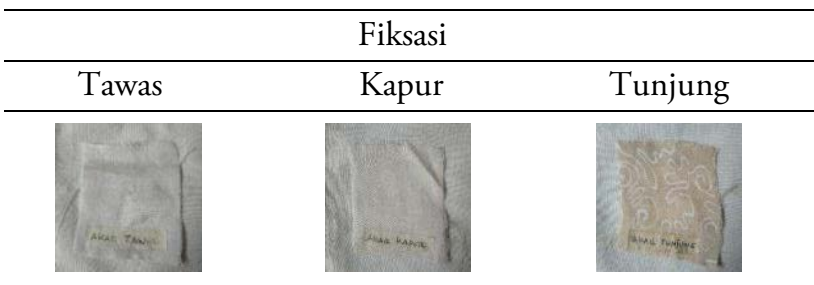

(Dengan Teknik (Dengan Teknik (Dengan Teknik Batik) Batik) Batik)

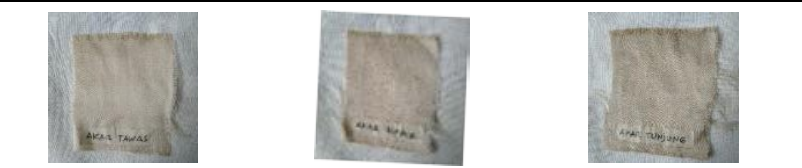

Hasil Eksperimen Ekstraksi Kulit Buah

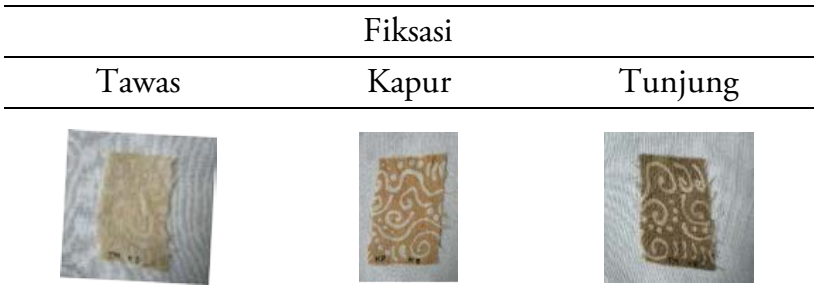

(Dengan Teknik (Dengan Teknik (Dengan Teknik Batik) Batik) Batik)
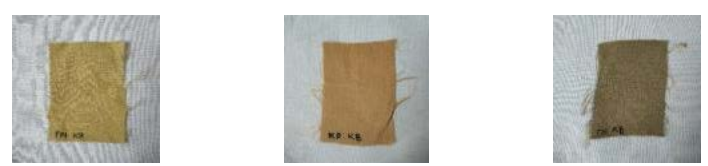

Tabel 2. Hasil Eksperimen Ekstraksi Kulit Kayu dan Ecoprint

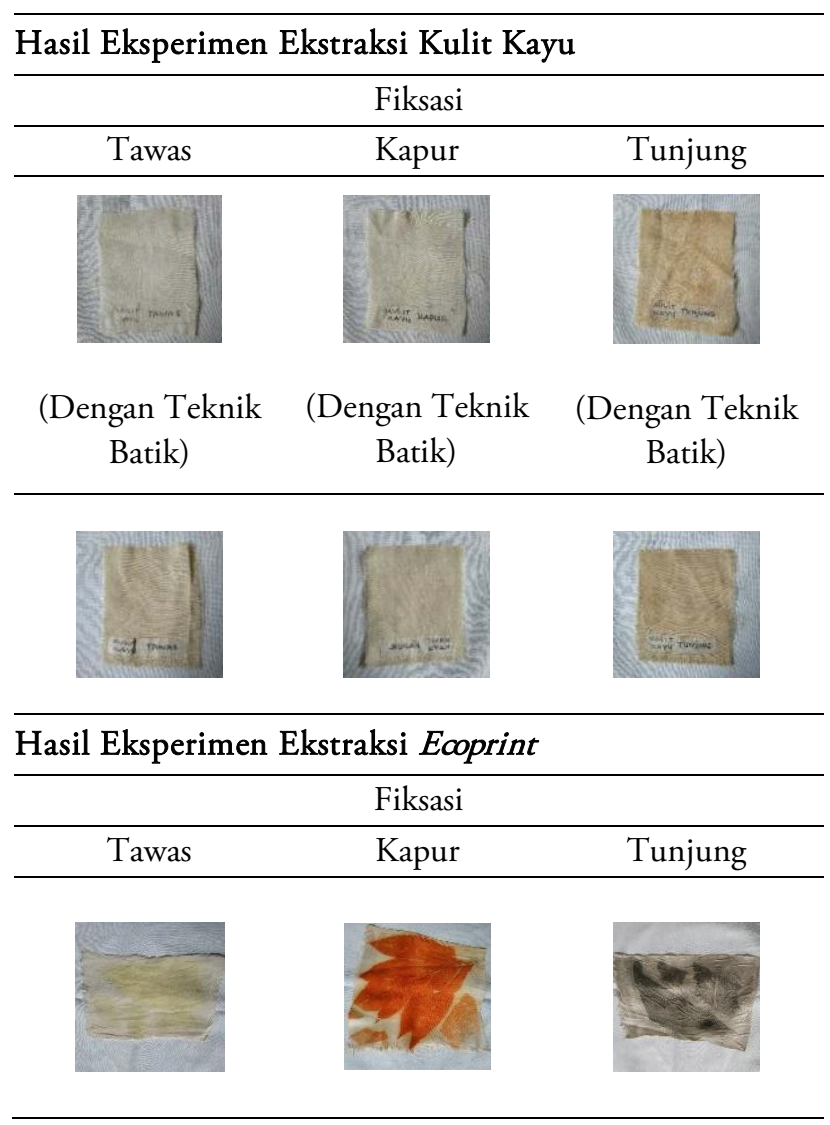

kurang lebih selama satu jam. Setelah dingin air rebusan disaring agar bersih dari ampas.

Pada eksperimen ekstraksi kulit kayu, bagian yang dipakai adalah kulit kayu dari pohon Kluwih. Pohon atau batang dikupas dahulu untuk diambil kulitnya saja dan kemudian direbus dalam 1 panci stainless atau email. Pengambilan warna dengan cara dasar ekstraksi yaitu bahan warna dicampur dengan air. Nol koma lima kilogram $(0,5 \mathrm{~kg})$ kulit kayu Kluwih ditindih menggunakan angsang lalu di atasnya diberi batu agar kulit kayu tidak naik ke atas dan air di atas angsang sekitar $2 \mathrm{~cm}$. Kulit kayu Kluwih direbus kurang lebih selama satu jam. Setelah dingin air rebusan disaring agar bersih dari ampas (Tabel 2).

Terakhir adalah eksperimen ecoprint. Pada tahap ini dilakukan percobaan pembuatan ecoprint menggunakan daun Kluwih sebagai pewarnaan alam secara langsung pada kain sutra. Pada tahap ini dilakukan tiga kali percobaan 
proses pembuatan teknik ecoprint. Hasilnya dapat dilihat pada Tabel 2.

\section{Kesimpulan}

Hasil eksperimen menunjukkan bahwa bagian-bagian dari pohon Kluwih yaitu daun, buah, kulit kayu, dan akar mempunyai kandungan pewarna yang berbeda kadar tone warnanya (tingkat warnanya). Perbedaan itu ditunjukkan dengan hasil dari fiksasinya sebagai berikut:

a. Daun. Hasil fiksasi dengan tawas, kapur, dan tunjung menunjukkan warna jelas dari kain tidak dibatik maupun yang dibatik.

b. Akar. Hasil fiksasi tawas dan kapur pada kain yang dibatik tidak memunculkan warna karena luntur. Hasil fiksasi tunjung pada kain yang dibatik menghasilkan warna soft. Hasil fiksasi tawas, kapur, dan tunjung pada kain tanpa batik menghasilkan warna soft.

c. Kulit Buah. Hasil fiksasi dengan tawas, kapur, dan tunjung yang menunjukkan warna jelas dari kain tidak dibatik maupun yang dibatik.

d. Kulit Kayu. Hasil fiksasi tawas dan kapur pada kain yang dibatik tidak memunculkan warna karena luntur. Hasil fiksasi tunjung pada kain yang dibatik menghasilkan warna soft. Fiksasi tawas, kapur, dan tunjung pada kain tanpa batik menghasilkan warna soft.

e. Ecoprint. Ecoprint dengan fiksasi tawas tidak memunculkan warna dan ecoprint dengan fiksasi kapur memunculkan warna hijau kehitam-hitaman.

Hasil eksperimen tersebut bagian kulit buah dan daun adalah bagian yang menghasilkan warna terbaik melalui proses celup. Sedangkan untuk proses ecoprint hanya bagian daun yang menghasilkan warna terbaik.

\section{Kepustakaan}

Gardjito, M., Winotosastro, H., \& Melati, K. R. (2018). Zat warna alam dan penggunaannya untuk pewarnaan batik. Yogyakarta: Paguyuban Pecinta Batik Indonesia Sekar
Jagad.

Gustami, S. P. (2007). Butir-butir mutiara estetika timur: ide dasar penciptaan seni kriya Indonesia. Yogyakarta: Prasista.

Gustami, S. P. (2008). Nukilan seni ornamen Indonesia. Arindo Nusa Media.

Jasper, J. E., \& Pirngadie, M. (1916). De Batikkunst: De Inlandsche Kunstnijverheid in Nederlandsch Indie Vol. 3. The Hague, Mouton \& Co.

Malins, J., Ure, J., \& Gray, C. (1996). The gap: Addressing practice-based research training requirements for designers. The Robert University, Aberdeen, United Kingdom.

McNiff, J., Lomax, P., \& Whitehead, J. (1996). You and your action research project. London: Routledge London.

Sedjati, D. P. (2019). Keben (Barringtonia Asiatica), motif dan pewarna batik. Corak: Jurnal Seni Kriya, 8(2), 98-107.

Sp, S. (1990). Tinjauan Seni: Sebuah Pengantar untuk Apresiasi Seni. Yogyakarta: Saku Dayar Sana.

Sp, S. (2006). Trilogi seni: penciptaan, eksistensi, dan kegunaan seni. Yogyakarta: Badan Penerbit Institut Seni Indonesia Yogyakarta.

Suheryanto, D. (2017). Natural Dyes: Ensiklopedia Zat Warna Alami dari Tumbuhan untuk Industri Batik. Yogyakarta: CV Andi Offset.

Suyanto, A. N. (1986). Batik Tradisional Yogyakarta Ditinjau Dari Aspek Motif Dan Makna Simboliknya. Proyek Peningkatan Pengembangan Pendidikan Tinggi, Fakultas Seni Rupa dan Desain, Institut Seni Indonesia Yogyakarta.

Suyanto, A. N. (2002). Sejarah Batik Yogyakarta. Yogyakarta: Rumah Penerbitan Merapi.

Widyaputri, S. D. (2020). Redesign pakaian secondhand berwarna putih dengan teknik batik tulis menggunakan pencelupan pewarna alami. Ars: Jurnal Seni Rupa Dan Desain, 23(3), 146-153. 